\title{
European phenological response to climate change matches the warming pattern
}

\begin{abstract}
ANNETTE MENZEL*, TIM H. SPARKS†, NICOLE ESTRELLA*, ELISABETH KOCH†, ANTO AASA, REIN AHAS§, KERSTIN ALM-KÜBLER-, PETER BISSOLLI\|, OL'GA BRASLAVSKÁ**, AGRITA BRIEDE††, FRANK M. CHMIELEWSKI ZALIKA CREPINSEK§§, YANNICKCURNEL『ฯ, ÅSLÖG DAHL\|\|,

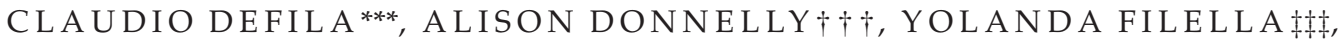

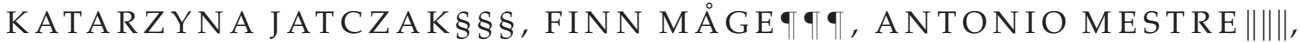
ØYVIND NORDLI***, JOSEP PENUELAS VIERA REMIŠOVÁ**, HELFRIED SCHEIFINGER , MARTIN STRIZ

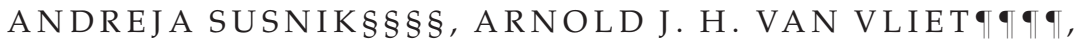
FRANS-EMIL WIELGOLASKI\|\|\|\|, SUSANNE ZACH

*Department of Ecology, Technical University Munich, 85350 Freising, Germany, $\dagger$ NERC Centre for Ecology and Hydrology, Monks Wood, Cambridgeshire PE28 2LS, UK, †Central Institute for Meteorology and Geodynamics, 1190 Vienna, Austria, §University of Tartu, 51014 Tartu, Estonia, -Swedish Museum of Natural History, 10405 Stockholm, Sweden, \|German Meteorological Service, 63067 Offenbach, Germany, **Slovak Hydrometeorological Institute, 83315 Bratislava 37, Slovak Republic, $\dagger \dagger$ Faculty of Geography and Earth Sciences, University of Latvia, Riga LV-1586, Latvia, $\ddagger \ddagger F a c u l t y$ of Agriculture and Horticulture, Humboldt-University, Berlin, 14195 Berlin, Germany, §§Biotechnical Faculty, University of Ljubljana, Ljubljana, Slovenia, - Centre Wallon de Recherches Agronomiques, 5030 Gembloux, Belgium, ||||Botaniska Analysgruppen i Göteborg, 40530 Göteborg, Sweden, ${ }^{* * *}$ MeteoSwiss, 8044 Zürich, Switzerland, $\dagger \dagger \dagger$ Department of Botany, Trinity College, Dublin 2, Ireland, $\ddagger \dagger \uparrow C e n t e r$ for Ecological Research and Forestry Applications CEAB-CSIC, Universitat Autònoma de Barcelona, 08193 Bellaterra, Catalonia, Spain, §§§Institute of Meteorology and Water Management, 01-673 Warszawa, Poland, $\uparrow \uparrow N o r w e g i a n$ University of Life Sciences, 1432 Ås, Norway, || ||||Instituto Nacional de Meteorología, 28040 Madrid, Spain, ${ }^{* * * * T h e ~ N o r w e g i a n ~ M e t e o r o l o g i c a l ~ I n s t i t u t e, ~} 0313$ Oslo, Norway, $+\dagger \dagger$ Finnish Meteorological Institute, 00101 Helsinki, Finland, $+\uparrow+\uparrow C z e c h$ Hydrometeorological Institute, Ostrava 70800, Czech Republic, §§§§Environmental Agency of the Republic of Slovenia, Ljubljana, Slovenia, $\uparrow \uparrow$ Wageningen University, 6700 AA Wageningen, The Netherlands, |||||||University of Oslo, 0316 Oslo, Norway
\end{abstract}

\begin{abstract}
Global climate change impacts can already be tracked in many physical and biological systems; in particular, terrestrial ecosystems provide a consistent picture of observed changes. One of the preferred indicators is phenology, the science of natural recurring events, as their recorded dates provide a high-temporal resolution of ongoing changes. Thus, numerous analyses have demonstrated an earlier onset of spring events for mid and higher latitudes and a lengthening of the growing season. However, published single-site or single-species studies are particularly open to suspicion of being biased towards predominantly reporting climate change-induced impacts. No comprehensive study or meta-analysis has so far examined the possible lack of evidence for changes or shifts at sites where no temperature change is observed. We used an enormous systematic phenological network data set of more than 125000 observational series of 542 plant and 19 animal species in 21 European countries (1971-2000). Our results showed that $78 \%$ of all leafing, flowering and fruiting records advanced (30\% significantly) and only $3 \%$ were significantly delayed, whereas the signal of leaf colouring/fall is ambiguous. We conclude that previously published results of phenological changes were not biased by reporting or publication predisposition: the average advance of spring/summer was 2.5 days decade ${ }^{-1}$ in Europe. Our analysis of 254 mean national time series undoubtedly demonstrates that species' phenology is responsive to temperature of the preceding
\end{abstract}

Correspondence: Annette Menzel, tel. + 498161 714743,

fax + 498161 714753, e-mail: menzel@forst.tu-muenchen.de

(C) 2006 The Authors

Journal compilation (C) 2006 Blackwell Publishing Ltd 
months (mean advance of spring/summer by 2.5 days ${ }^{\circ} \mathrm{C}^{-1}$, delay of leaf colouring and fall by 1.0 day ${ }^{\circ} \mathrm{C}^{-1}$ ). The pattern of observed change in spring efficiently matches measured national warming across 19 European countries (correlation coefficient $r=-0.69, P<0.001)$.

Key words: climate change, Europe, growing season, meta analysis, phenology, season, temperature response, trend

Received 30 January 2006; revised version received 28 March 2006; accepted 3 April 2006

\section{Introduction}

Many studies examining the impacts of global warming on terrestrial ecosystems reveal a consistent pattern of change, the response to warming by phenological change across the northern hemisphere seems to be especially well documented (IPCC, 2001; Sparks \& Menzel, 2002; Walther et al., 2002; Parmesan \& Yohe, 2003; Root et al., 2003). The majority of the published studies focus on the question of whether changes in systems and sectors relate to changing regional climates. As a consequence of this bulk of studies, further reporting of phenological trends in peer-reviewed journals may become more and more difficult, especially when 'simply' dealing with 'no change' or 'change opposite to the direction expected' (Hughes, 2000; Kozlov \& Berlina, 2002; Menzel, 2002). Thus, there exists the danger of reporting or publication bias of these observed impacts. In principle, four combinations of system and climate changes are possible (Fig. 1). 'No change' in the tracking systems seems to be less likely to be reported, especially if it matches with 'no change' in temperatures. However, this combination also emphasises consistency with the functional understanding of the system and predicted climate responses.

Within the Intergovernmental Panel on Climate Change (IPCC), Working Group II on Impacts, Adaptation and Vulnerability is involved with an assessment of observed changes for its next report (AR4, April 2007). Here, it is extremely important to keep track of the

\begin{tabular}{|c|c|c|}
\hline & \multicolumn{2}{|c|}{ Climate } \\
\hline & Change & No change \\
\hline$=\frac{\substack{\mathscr{E} \\
\frac{\pi}{0}}}{0}$ & $\begin{array}{l}\text { Most likely } \\
\text { to be published, } \\
\text { especially when as } \\
\text { expected }\end{array}$ & $\begin{array}{l}\text { Likely } \\
\text { to be published, } \\
\text { explained by other } \\
\text { drivers }\end{array}$ \\
\hline 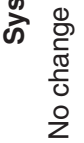 & $\begin{array}{l}\text { Unlikely } \\
\text { to be published, } \\
\text { explained by other } \\
\text { drivers }\end{array}$ & $\begin{array}{l}\text { Unlikely } \\
\text { to be analysed } \\
\text { or reported }\end{array}$ \\
\hline
\end{tabular}

Fig. 1 Categories of system responses to observed changes and nonchanges in climate and relation to publication biases. entirety of changes in order to properly address the questions of evidence of no change, change opposite to the direction expected, change not matching climate/ temperature change, and to discuss the questions of resilience and thresholds.

Two recent meta-analyses have summarized the coherent picture of a global 'fingerprint' of climate change. Parmesan \& Yohe (2003) included multispecies studies from any location that reported neutral, negative and positive results and analysed a total of 677 species or species functional groups' phenology. However, the results of one study site in the United Kingdom (Fitter \& Fitter, 2002) alone accounted for nearly half of its records. A second meta-analysis was restricted to publications reporting significant changes of one or many species (Root et al., 2003). Consequently, the average spring advance revealed by the latter was higher (5.1 compared with 2.3 days decade ${ }^{-1}$ ). Metaanalyses which include reanalyses of network data for all available species do not yet exist. Thus, the goal of the present study was an exhaustive Europe-wide analysis of all observed changes in phenology (plants/ animals) in the period 1971-2000. Owing to the systematic (re-)analysis of all available records, including those from dense phenological networks, this metaanalysis allows, for the first time, a methodical review of absence of evidence and of possible reporting or publication bias. By incorporating monthly temperature series for countries, we were able also to quantify the species' responsiveness to temperature.

\section{Material and methods}

An extremely abundant data set of trends in European phenological phases was systematically collected within the COST action 725 'Establishing a European phenological data platform for climatological applications' (http://www.cost725.org) comprising all phenological records digitally available at present. It included entire phenological networks of 11 countries (Austria, Belgium, Czech Republic, Estonia, Germany, Latvia, Poland, Slovakia, Slovenia, Switzerland, Russia (provided by the 5FP project POSITIVE)), five specialists networks (Finland, Spain, the Netherlands, Norway, 
United Kingdom) and the network of the International Phenological Gardens in Europe (http://www.agrar.huberlin.de/pflanzenbau/agrarmet/ipg_en.html), spreading over 14 countries including, in addition to countries named above, Croatia, Denmark, Greece, Ireland and Macedonia. In total, phenological trends of 542 plant species in 21 countries (125628 time series) and 19 animal species in three countries (301 time series) were analysed. The phenophases of wild plants, fruit trees and agricultural crops were assigned to a $\mathrm{BBCH}$ (Biologische Bundesanstalt, Bundessortenamt and CHemical Industry) code (Meier, 1997) and grouped either by $\mathrm{BBCH}$ code or $\mathrm{BBCH}$ subgroups (principal growth stages). If applicable, agricultural and natural phases were treated separately.

Annual mean onset dates for nine countries (Austria, Belarus/northern Russia, Estonia, Czech Republic, Germany, Poland, Slovenia, Switzerland, Ukraine/ southern Russia), comprising 254 records (phenophases $\times$ countries) of $10+$ years, however, mostly covering the total period 1951-1999, were available for the quantitative assessment of temperature responses. Annual, monthly and seasonal temperature means for all European countries (1901-2000) were used from the Tyndall Centre (Mitchell et al., 2002, 2004).

Annual mean onset dates were correlated by Pearson's product moment correlation with three mean monthly temperatures (the month of mean onset, and the two preceding months) of the respective country. The highest correlation coefficient of these three served as a measure for the temperature responsiveness of the respective phenophase in that country. The slopes of linear regressions of the annual mean dates against the mean temperature of the month before the event provided a measure for the temperature sensitivity. These regression coefficients were analysed in total, by mean onset date, by phenophase group and for selected species $\times$ country combinations.

Each of the COST725 team member states contributed a countrywide trend analysis (1971-2000) including mean onset dates and their standard deviation, linear regressions of the onset dates against year including slope of the regression, standard error of the slope and significance of the regression by $F$-test. In the subsequent meta-analysis (103199 records of $15+$ years) these trends were analysed for Europe by four phenophase groups (b0, farmers' activities; b1, flowering and leaf unfolding; b2, fruiting; b3, leaf colouring), for countries by phenophase groups, and for countries and species.

\section{Results}

We found that phenological changes were a clear reaction to temperature. Figure 2a displays all correlation coefficients of 254 mean national records with tempera- ture. Most phases correlated significantly with mean monthly temperatures of the month of onset and the two preceding months. For 19\% of the phenophases the highest correlation was with the month of onset, $63 \%$ with preceding month and 18\% with 2 months earlier. The average correlation coefficients for four groups (farmers' activities, spring and summer phases, fruit ripening, leaf colouring) are given in Table 1; their means all clearly differed from 0 ( $t$-tests, b0-b2 $P<0.001$, b3 $P<0.007)$. Analysis of variance followed by Tukey's HSD showed that there were significant differences $(P<0.001)$ between the groups in their average correlation with temperature, all of which differed from one another except farmers' activities and fruit ripening.

For spring and summer, and most of the autumn fruit ripening phases, the mean correlation coefficient was negative. Thus, higher temperatures were related to earlier onset dates. The mean value for flowering (Fig. 2a, $\bar{r}=-0.69)$ and other spring phases, such as leaf unfolding and budburst of wild plants $(\bar{r}=-0.69)$, shooting and closure of the stands $(\bar{r}=-0.62)$ as well as ear formation $(\bar{r}=-0.55)$ of agricultural crops displayed quite similar temperature sensitivity. Farmers' activities, such as drilling, tilling, harvesting, known as 'false phases', which respond to a lesser degree to climate, also revealed a quite high mean correlation with temperature $(\bar{r}=-0.53)$. Only the emergence and sprouting of agricultural winter crops in autumn, which is very much related to harvesting and subsequent drilling, were less related to temperature $(\bar{r}=-0.28)$. Earlier fruit ripening was connected to warmer summers $(\bar{r}=-0.45)$; only for Aesculus hippocastanum in Switzerland and Slovenia was there an opposite relationship. Fruit ripening of agricultural plants was more closely related to temperature $(\bar{r}=-0.57)$ than wild plants $(\bar{r}=-0.29)$. Delayed leaf colouring was associated with higher temperatures $(\bar{r}=+0.33)$; only in eastern Europe (Russia-Belarus, Russia-Ukraine and Czech Republic) did warming result in earlier leaf colouring. There was a clear dependence of the temperature sensitivity on mean timing as earlier phases and very late phases had the highest correlation, negative and positive, respectively, with temperature.

The temperature response was assessed by the slope of linear regression of mean date on mean temperature of the month before onset (Fig. 2b). Spring and summer phases advanced by up to 4.6 days ${ }^{\circ} \mathrm{C}^{-1}$ warming (two outliers in summer are related to agricultural phases in Germany) and autumn leaf colouring was delayed by up to 2.4 days ${ }^{\circ} \mathrm{C}^{-1}$. Overall, mean onset dates influenced the temperature response, the mean for autumn phases $\left(+0.98\right.$ days $\left.{ }^{\circ} \mathrm{C}^{-1}\right)$ did differ significantly from the other three groups' means $(-2.10,-2.52$ and -2.18 


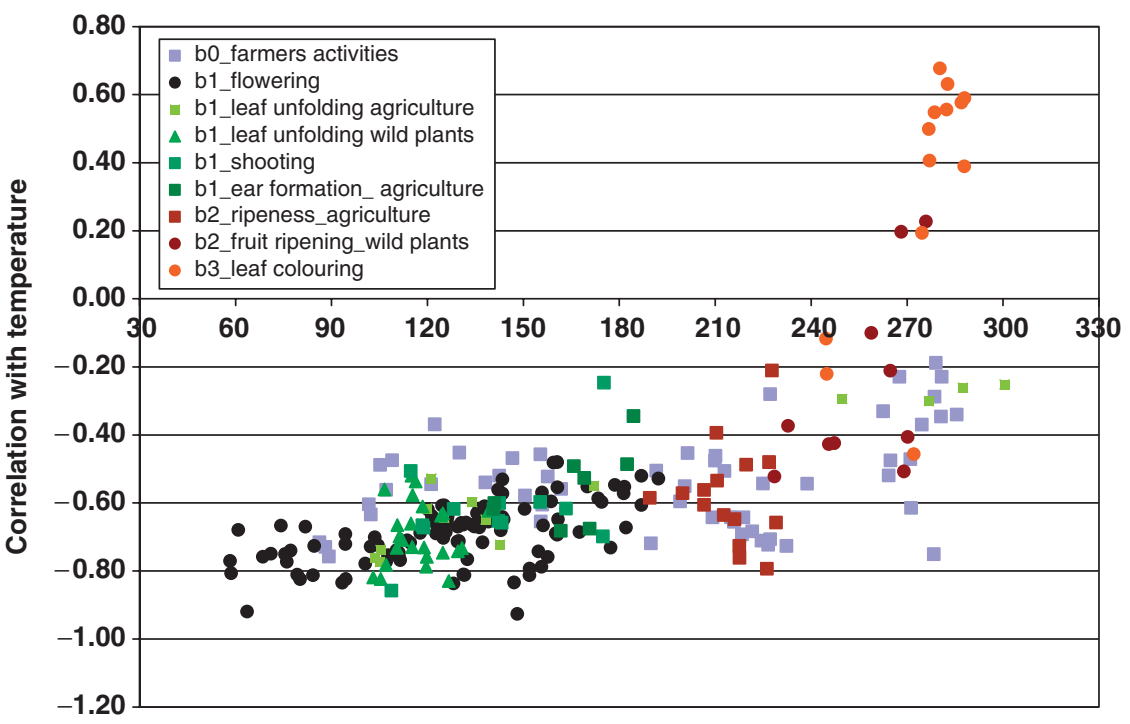

Mean date (day of year)

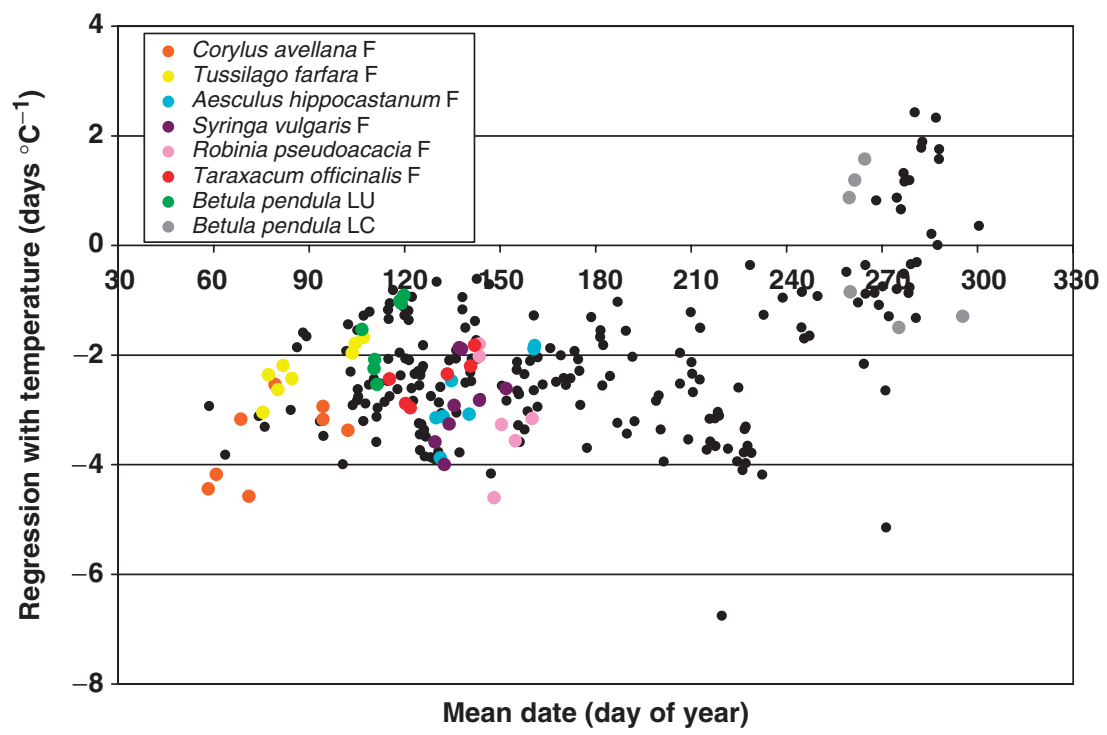

Fig. 2 Temperature sensitivity and response across the year. (a) Maximum correlation coefficients of 254 mean national time series in nine European countries (see 'Material and methods') with mean temperatures of the previous months. Phenophases groups include farmers' activities (b0), spring and summer with different leafing, shooting and flowering phases (b1), autumn fruit ripening (b2) and leaf colouring of deciduous trees in fall (b3). (b) Regression coefficients against mean temperature of the previous month. F, flowering; LU, leaf unfolding; LC, leaf colouring. The overall dependence of temperature sensitivity and response on mean date is high (a) $R^{2}=0.59, y=0.0000003 x^{3}-0.0001204 x^{2}+0.0182684 x-1.5823, P<0.001 ;(b) R^{2}=0.47, y=0.0000024 x^{3}-0.0011345 x^{2}+0.170218 x-10.4650$, $P<0.001)$.

days ${ }^{\circ} \mathrm{C}^{-1}$ ) (Table 1). Phases analysed for more than six countries are highlighted in Fig. 2b: All spring phases, except Robinia pseudoacacia flowering, exhibited a stronger response to temperature in warmer than in colder countries. The regression coefficients of the temperature sensitivity against mean onset date of flowering (days ${ }^{\circ} \mathrm{C}^{-1}$ per day of the year) were $0.028\left(R^{2}=0.37\right)$ for Corylus avellana, $0.030\left(R^{2}=0.78\right)$ for Tussilago farfara, $0.047\left(R^{2}=0.74\right)$ for A. hippocastanum, $0.049\left(R^{2}=0.21\right)$ for Syringa vulgaris, $0.029\left(R^{2}=0.60\right)$ for Taraxacum officinalis, and, in contrast, $-0.072\left(R^{2}=0.21\right)$ for $R$. pseudoacacia. For Betula pendula, both the rate of advance of leaf unfolding and the rate of delay of leaf colouring per ${ }^{\circ} \mathrm{C}$ temperature rise were also higher in (warmer) countries with earlier mean onset (regression coefficients $0.093, R^{2}=0.54$ and $-0.062, R^{2}=0.40$, respectively).

All observed changes in Europe (1971-2000, 103199 time series with $15+$ years) are summarized in Table 2 
Table 1 Mean temperature sensitivity and response of phenological phases

\begin{tabular}{|c|c|c|c|c|}
\hline \multicolumn{2}{|c|}{ Phenophase group } & \multirow{2}{*}{$\frac{n}{54}$} & \multirow{2}{*}{$\begin{array}{l}\text { Mean } \pm \text { SE of correlation coefficient } \\
-0.53 \pm 0.02\end{array}$} & \multirow{2}{*}{$\begin{array}{l}\text { Mean } \pm \text { SE of regression coefficient } \\
-2.10 \pm 0.16\end{array}$} \\
\hline $\mathrm{b} 0$ & Farmers activities & & & \\
\hline b1 & Leaf unfolding, flowering & 160 & $-0.66 \pm 0.01$ & $-2.52 \pm 0.07$ \\
\hline b2 & Fruit ripening & 25 & $-0.45 \pm 0.05$ & $-2.18 \pm 0.34$ \\
\hline b3 & Leaf colouring & 13 & $+0.33 \pm 0.10$ & $+0.98 \pm 0.37$ \\
\hline
\end{tabular}

Correlation and regression coefficients (slopes) of annual mean phenological records for nine European countries (see 'Material and methods') against mean monthly temperatures of the respective country (the month of mean onset, and the two preceding months); (see 'Material and methods').

Table 2 Summary of phenological trends in Europe

\begin{tabular}{|c|c|c|c|c|c|c|c|c|}
\hline \multicolumn{2}{|c|}{ Phenophase group } & \multirow{2}{*}{$\begin{array}{l}n \\
22338\end{array}$} & \multirow{2}{*}{$\begin{array}{l}\text { Neg_all } \\
0.57\end{array}$} & \multirow{2}{*}{$\begin{array}{l}\text { Neg_sig } \\
0.13\end{array}$} & \multirow{2}{*}{$\begin{array}{l}\text { Pos_all } \\
0.43\end{array}$} & \multirow{2}{*}{$\begin{array}{l}\text { Pos_sig } \\
0.06\end{array}$} & \multirow{2}{*}{$\begin{array}{c}\operatorname{Tr}_{\text {mean }} \\
-0.041\end{array}$} & \multirow{2}{*}{$\frac{\operatorname{avTr}_{\text {mean }}}{-0.060}$} \\
\hline $\mathrm{b} 0$ & Farmers activities & & & & & & & \\
\hline b1 & Leaf unfolding, flowering & 64027 & 0.78 & 0.31 & 0.22 & 0.03 & -0.250 & -0.200 \\
\hline b2 & Fruit ripening & 11191 & 0.75 & 0.25 & 0.25 & 0.03 & -0.237 & -0.190 \\
\hline b3 & Leaf colouring & 5643 & 0.48 & 0.12 & 0.52 & 0.15 & 0.017 & 0.129 \\
\hline$b 1+b 2$ & Leaf unfolding, flowering, fruit ripening & 75218 & 0.78 & 0.30 & 0.22 & 0.03 & -0.248 & -0.198 \\
\hline
\end{tabular}

All temporal trends (1971-2000, time series of 15+ years) which have been systematically reported to the COST725 meta-analysis $(n=103199)$ for four different groups. Neg_all/Pos_all proportions of negative and positive trends, Neg_sig/Pos_sig proportions of significantly negative and positive trends $(P<0.05)$, $\operatorname{Tr}_{\text {mean }}$ mean slopes for Europe (days $\left.\mathrm{yr}^{-1}\right)$, avTr $\mathrm{Tr}_{\text {mean }}$ average of national mean slopes (days $\mathrm{yr}^{-1}$ ) to adjust for different station numbers in the different national networks.

by sign, significance, and means of the trends. In general, for farmers' activities and especially spring, summer, as well as fruit ripening phases, there were more negative than positive trends (i.e. more time series revealed advancing onset), in contrast to leaf colouring and leaf fall phases where we had almost the same proportion of negative and positive trends (Fig. 3). Thus, there is a clear signal across Europe of changing spring and summer phenology with $78 \%$ of leaf unfolding and flowering records advancing (31\% significantly) and only $22 \%$ delayed (3\% significantly). The signal in farmers' activities was generally smaller (57\% advancing, $13 \%$ significantly, $43 \%$ delayed, $6 \%$ significantly). In contrast to spring events, the signal for leaf colouring in fall is quite ambiguous (48\% advancing, $52 \%$ delayed) and less apparent as there were similar proportions of negative and positive significant trends. It is important to note that fruit ripening of different species was mostly advanced (75\% negative, $25 \%$ significantly negative; $25 \%$ positive, $3 \%$ significantly positive trends). The total signal for spring and summer phenology including fruit ripening of wild plants was apparent with almost $80 \%$ advancing time series. These results strongly support previous results on a smaller number of sites and species and confirm them as being free from bias towards reporting global change impacts. Average trends in farmers' activities were small (Table 2), while those of leafing, flowering and fruiting show a clear advance of 2.5 days decade ${ }^{-1}$. Leaf colouring and fall trends were close to 0 , but suggested more of a delay when the average trend per country is examined (1.3 days decade ${ }^{-1}$ ).

When analysing the country means of the trends we found, for the first time, that phenology is not only a good bio-indicator for temperature changes in general, but also mirrored them quantitatively. Average phenological trends for countries systematically varied with temperature changes of the same country. Thus, for spring, our analysis revealed higher negative (advancing) trends of flowering and leaf unfolding in countries which exhibit a stronger warming in the preceding month (1971-2000; $r=-0.69, P<0.001,19$ countries, Fig. 4a). Even the average trends of animal spring phases in three countries fitted perfectly into the relationship between phenological and temperature trends. Mean fruit ripening trends in eight European countries matched national temperature changes of the previous month quite well ( $r=-0.66, P=0.076$, Fig. $4 \mathrm{~b})$. For leaf colouring and leaf fall in autumn, there is no clear relationship between national phenological and temperature trends $(r=0.003, P=0.99,14$ countries, Fig. 4c). Even for single species, such as leaf unfolding of Fagus sylvatica and flowering of Prunus avium, their mean national trends match the pattern of temperature increase in March (F. sylvatica $r=-0.86, P=0.003$, nine countries, Fig. $4 \mathrm{~d}$; $P$. avium $r=-0.73, P=0.004,13$ countries, Fig. 4e). 

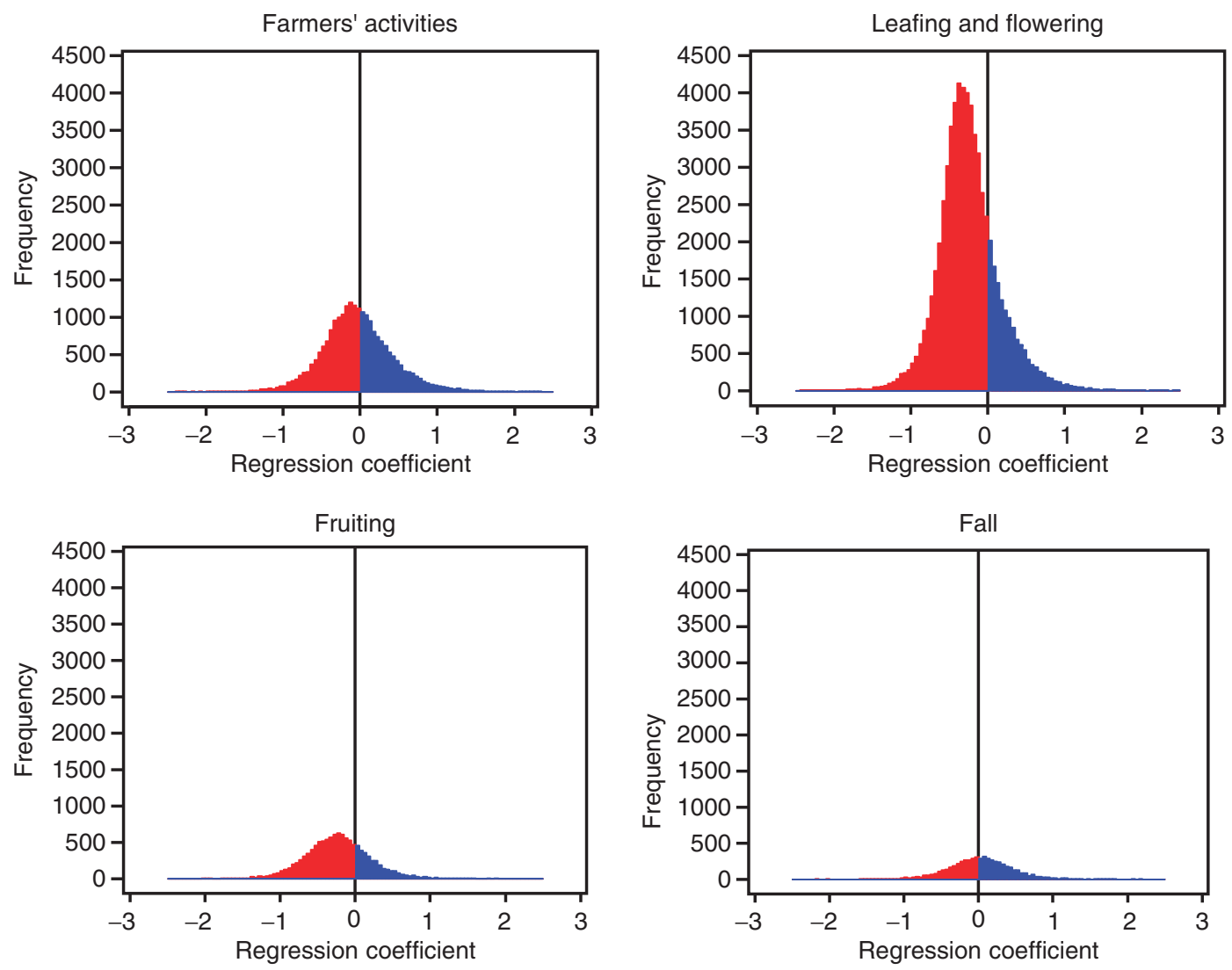

Fig. 3 Histograms of phenological trends in Europe. All temporal trends (1971-2000, time series $15+$ years) as linear regression coefficients $\left(\right.$ days $\mathrm{yr}^{-1}$ ) systematically reported to the COST725 meta-analysis $(n=103199)$ for four different groups.

\section{Discussion}

Our meta-analysis comprised a huge selection of species and countries, included false phases in farming, and various phases of wild and agricultural plants covering the whole vegetation period. Owing to the enormous number of records included, the results are representative for Europe. The temperature response of spring phenology was unquestionable. We found that the earlier species were more sensitive, probably because of higher temperature variability in spring months, and they better indicated changes in temperature. The autumn signal was vague (delayed leaf colouring, but earlier fruit ripening because of warming, the latter more pronounced in agricultural than wild plants), thus further studies about observed climate change impacts in autumn should clearly differentiate between these phases. The temperature response varied between -4.6 days ${ }^{\circ} \mathrm{C}^{-1}$ in spring and +2.4 days ${ }^{\circ} \mathrm{C}^{-1}$ in autumn, early spring phases again had the strongest reactions. Our important finding, that all spring phases within European countries, except R. pseudoacacia flowering, exhibited a stronger response to temperature in warmer countries with earlier mean onset dates, may allow future parametrization of simple site-specific phenological models where no data were observed.

We would recommend further study to consider some questions arising from this study. Why is responsiveness to temperature greater in warmer countries? Will increased autumn temperatures hinder vernalization and thus delay spring? Will this interfere with spring temperatures advancing spring? To what extent does rainfall and soil moisture influence phenology, particularly of leaf colouration phases? We trust that these, and other questions, can be addressed under COST725 auspices on the European datasets it is assembling.

Our first systematic meta-analysis of more than 100000 phenological time series in Europe clearly confirmed that there was no reporting or publication bias in earlier studies. There is an evident signal of advancing leaf unfolding, flowering and fruiting in wild plants all across Europe apparent in almost $80 \%$ of the records. The mean advance of spring in Europe of 2.5 days decade $^{-1}$ matches previous results for the continent (Menzel \& Fabian, 1999) and is slightly above results 

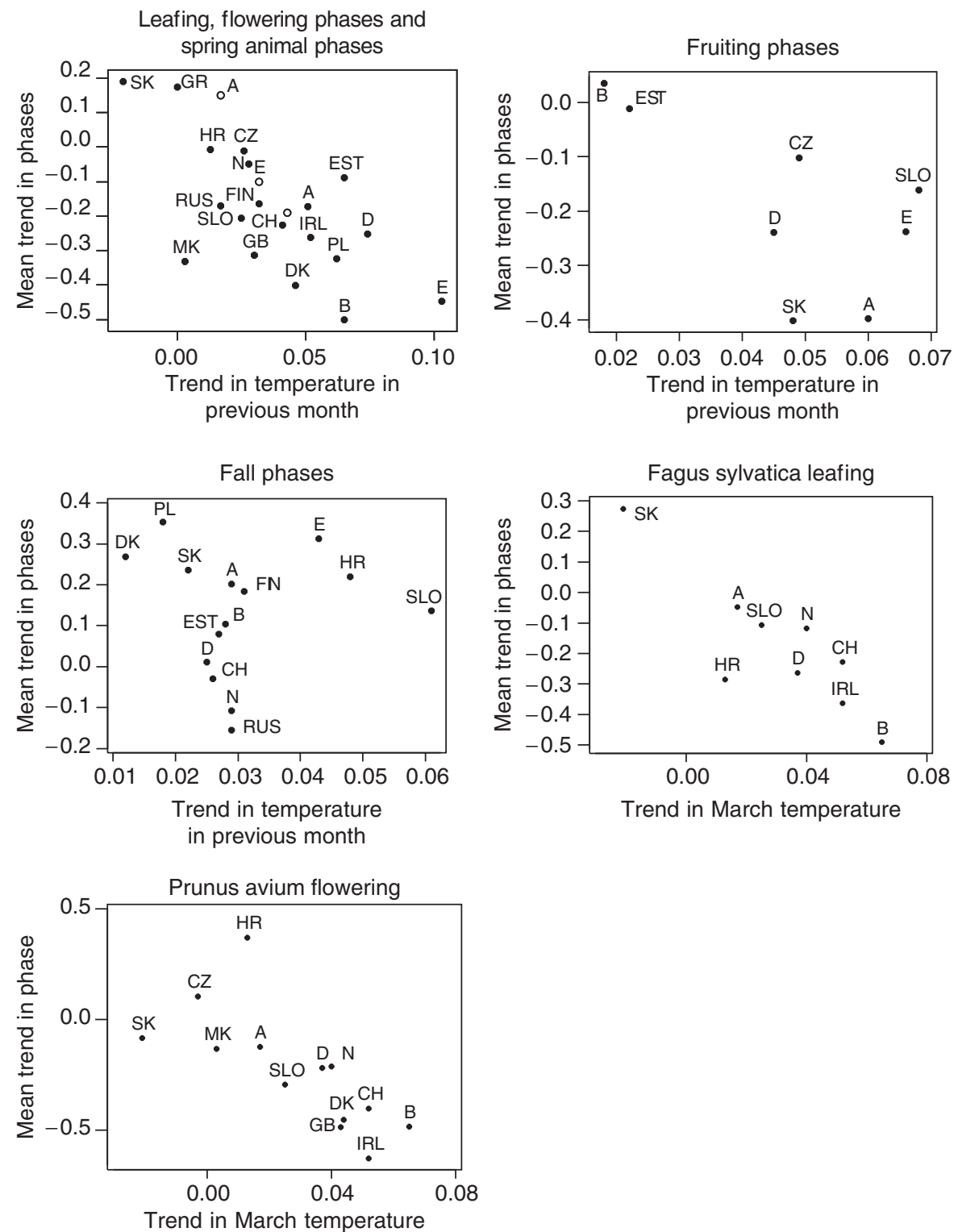

Fig. 4 National mean temperature trends against mean phenological trends. (a) In spring and summer (leaf unfolding, flowering closed circles, animal phases - open circles). (b) In summer and early autumn (fruit ripening). (c) In autumn (leaf colouring and leaf fall). (d) For leaf unfolding of Fagus sylvatica and (e) for flowering of Prunus avium. Country abbreviations follow the international country codes.

for a few countries in Central Europe (Defila \& Clot, 2001, 2005; Menzel, 2003), however, in accordance with them, as our study period was restricted to the last three decades characterized by a stronger warming trend. Leaf colouring and leaf fall were less frequently observed; the majority of trends analysed were from Germany where, on average, no trend in leaf colouring was found (Fig. 4c; Menzel, 2003). Thus, our summary of all trends revealed no clear signal of leaf colouring changes in the last three decades, whereas results for other European countries based on fewer records showed delayed autumn (Menzel \& Fabian, 1999; Defila \& Clot, 2001). Normalized difference vegetation index (NDVI); Myneni et al., 1997; Zhou et al., 2001) and the $\mathrm{CO}_{2}$ signal (Keeling et al., 1996) provide spatially and species-averaged information on the start and end of the growing season. Confined to shorter time spans starting in 1981 (NDVI), their lengthening of the growing season peak at about 10 days decade $^{-1}$ for Eurasia (Zhou et al., 2001), probably due to the fact that 
ground-based visible colouring or leaf fall occurs later than the end of the growing season derived by NDVI or that the magnitudes derived by NDVI data depends on their coarse temporal resolution. The spring phenological signal, however, is a perfect indicator for climate change impacts, as observed advances quantitatively mirror the measured warming.

\section{Acknowledgements}

We thank all anonymous observers in the European national phenological networks for their valuable work and two anonymous referees for the helpful comments. This study was supported by a travel grant from the COST action (A. M.).

\section{References}

Defila C, Clot B (2001) Phytophenological trends in Switzerland. International Journal of Biometeorology, 41, 203-207.

Defila C, Clot B (2005) Phytophenological trends in the Swiss Alps, 1951-2002. Meteorologische Zeitschrift, 14, 191-196.

Fitter AH, Fitter RSR (2002) Rapid changes in the flowering time in British plants. Science, 296, 1689-1691.

Hughes L (2000) Biological consequences of global warming: is the signal already apparent? Trends in Ecology and Evolution, 15, 56-61.

Keeling CD, Chin JFS, Whorf TP (1996) Increased activity of northern vegetation inferred from atmospheric $\mathrm{CO}_{2}$ measurements. Nature, 382, 146-149.

Kozlov MV, Berlina NG (2002) Decline in length of the summer season on the Kola Peninsula, Russia. Climatic Change, 54, 387-398.

IPCC (2001) Contribution of working group II to the third assessment report of the intergovernmental panel on climate change. In: Climate Change 2001: Impacts, Adaptations, and
Vulnerability (eds McCarthy JJ, Canziani OF, Leary NA, Dokken DJ, White KS), p. 1032. Cambridge University Press, New York.

Meier U (1997) BBCH-Monograph. Growth stages of plants Entwicklungsstadien von Pflanzen - Estadios de las plantas Développement des Plantes. Blackwell Wissenschaftsverlag, Berlin und Wien.

Menzel A (2002) Phenology: its importance to the global change community. Climatic Change, 54, 379-385.

Menzel A (2003) Plant phenological anomalies in Germany and their relation to air temperature and NAO. Climatic Change, 57, 243-263.

Menzel A, Fabian P (1999) Growing season extended in Europe. Nature, 397, 659.

Mitchell TD, Carter TR, Jones PD et al. (2004) A comprehensive set of high-resolution grids of monthly climate for Europe and the globe: the observed record (1901-2000) and 16 scenarios (2001-2100). Tyndall Working Paper 55, July 2004, pp. 1-30.

Mitchell TD, Hulme M, New M (2002) Climate data for political areas. Area, 34, 109-112.

Myneni RB, Keeling CD, Tucker CJ et al. (1997) Increased plant growth in the northern high latitudes from 1981 to 1991. Nature, 386, 698-702.

Parmesan C, Yohe G (2003) A globally coherent fingerprint of climate change impacts across natural systems. Nature, 421, 37-42.

Root TL, Price JT, Hall KR et al. (2003) Fingerprints of global warming on wild animals and plants. Nature, 421, 57-60.

Sparks TH, Menzel A (2002) Observed changes in the seasons: an overview. International Journal on Climatology, 22, 1715-1725.

Walther GR, Post E, Convey P et al. (2002) Ecological responses to recent climate change. Nature, 416, 389-395.

Zhou LM, Tucker CJ, Kaufmann RK et al. (2001) Variations in northern vegetation activity inferred from satellite data of vegetation index during 1981 to 1999. Journal of Geophysiology Research, 106, 20069-20083. 